\title{
QUALITATIVE ANALYSIS OF PHYTOCHEMICALS IN SELECTED SEAWEEDS OF MANDAPAM COAST, RAMESWARAM, INDIA
}

\author{
Maria Puspham Grace ${ }^{1}$, M Rajithra R ${ }^{2}$, V.Ilakkiya ${ }^{3}$, Dr.B.Dhanalakshmi ${ }^{4}$ \\ ${ }^{1234}$ Department of Zoology, Nirmala College for Women, Bharathiyar University, Coimbatore-18
}

Article DOI: https://doi.org/10.36713/epra6783

DOI No: 10.36713/epra6783

\begin{abstract}
In the world, seaweeds or marine macro algae area unit is renewable living resources that are used as a several components like food, feed, and fertilizers. They are typically live hooked up to rock or alternative laborious substrata in coastal areas. Turbinaria found in tropical marine waters, which grows on rocky substrates. Turbinaria belongs to the class- Anthozoa, Order-Scleractinia, family-Dendrophylliidae, Genus- Turbinaria. The aim of the present study is the phytochemical analyses were evaluated for the marine algae Turbinaria conoides and Turbinaria ornate from Mandapam coast, Rameswaram, Tamil Nadu, India. To cope with the assessment of the chemical composition of assorted marine seaweeds were extracted from different solvents. The current study reveals that the seaweeds contain a high quantity of phytochemical constituents. Besides, the presence of alkaloids, terpenoids, steroids, tannins, saponins, flavonoids, phenols, coumarins, proteins, carbohydrates, quinones and glycosides from Turbinaria ornata and Turbinaria conoides. This report will lead to the isolation and characterization of these active secondary metabolites for bio-efficacy and bioactivity. Therefore, seaweed extracts possessed higher amount of phytochemicals and which proves that these selected seaweeds will have provide unique and novel metabolites of unprecedented structures, with antibacterial, antifungal, antiviral, anti-plasmodial, nematicidal, anti-inflammatory, anticancer, and anti-angiogenic activities, these bioactive compounds may provide high-quality drug candidates for pharmaceutical applications, as well as agricultural and industrial applications.
\end{abstract}

KEYWORDS: Turbinaria, Coumarins, Seaweeds, Phytochemicals and Turbinaria conodies 


\section{EPRA International Journal of Research and Development (IJRD)}

\section{INTRODUCTION}

India (08.04-37.06 N and 68.07-97.25 E), a tropical South Asian country (Figure 1) has a stretch of about $7500 \mathrm{~km}$ coastline, excluding its island territories with 2 million $\mathrm{km} 2$ Exclusive Economic Zone (EEZ) and nine maritime states. The seaweed flora of India is highly diversified and comprises mostly of tropical species, but boreal, temperate and subtropical elements have also been reported. In all, 271 genera and 1153 species of marine algae, including forms and varieties have been enumerated till date from the Indian waters (Anon, 2005). More than 10,000 species of marine algae have been reported all over the world. In India, about 220 genera and 740 species of marine algae were recorded of which 60 species are of economic value. Tamil Nadu has a geographical extent of $1,30,058 \mathrm{~m}^{2}$. The coast of Tamil Nadu bears luxuriant growth of seaweeds. Several species of green, brown and red algae with luxuriant growth occur along the Southern Tamil Nadu Coast from Rameswaram to Kanyakumari covering 21 islands of Gulf of Mannar. More than two hundred species of seaweeds have found in this area. Rich seaweed beds are present at Mumbai, Ratnagiri, Goa, Karwar, Varkala, Vizhinjam, Visakhapatnam and coastal lakes of Pulicat and Chilka. Seaweeds also occur abundantly in Lakshadweep Andaman and Nicobar Islands (Plate: 1).

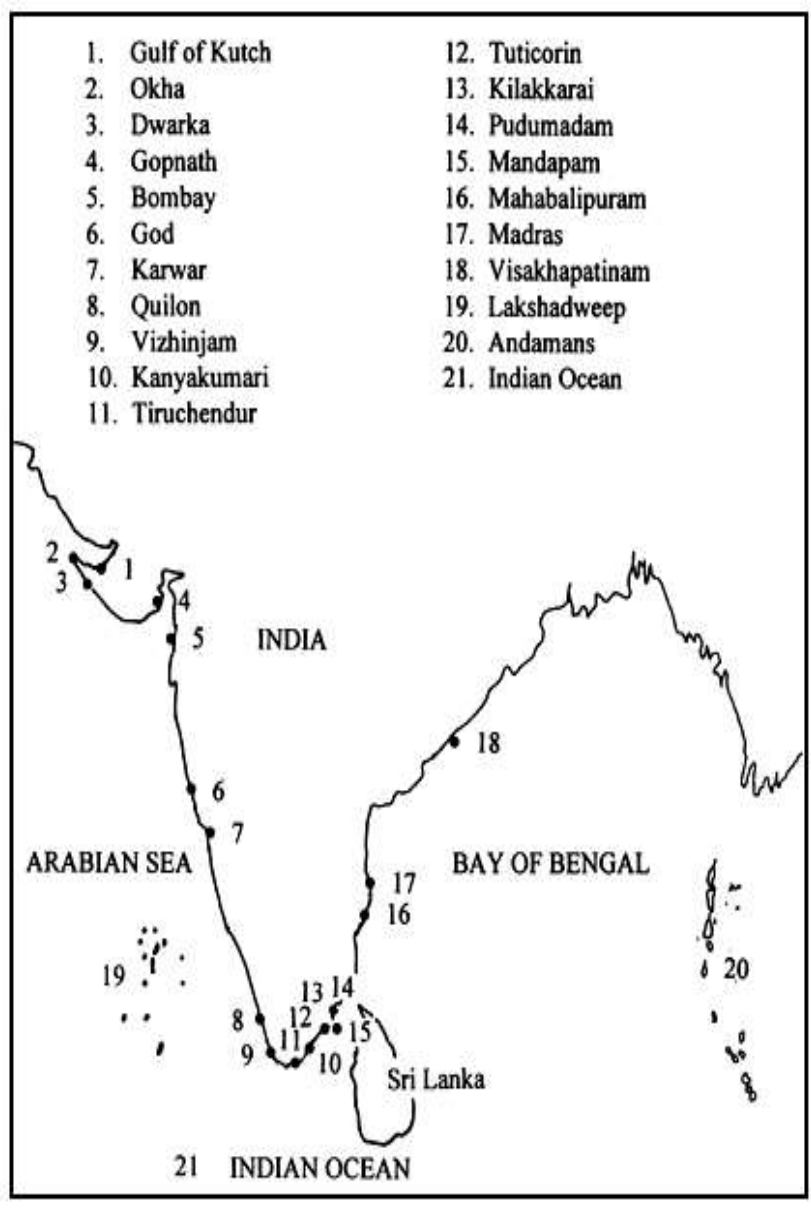

Plate: 1 Biodiversity of seaweed in India

Brown seaweeds are the largest group of marine macroalgal species found in oceans. Gulf of Mannar located in Southeast coast of India is being flourished with brown seaweeds, particularly belonging to the group Fucales (Li et al., 2009; Maria Jose Perez et al., 2016). In the immense coastal areas, they play a major role in maintaining the marine ecosystem. Consumption of brown seaweed is higher than red and green seaweeds and the amount of 
seaweed harvesting is increasing every year worldwide (Barsanti \& Gualtieri, 2006) mainly for food and for its cell wall polysaccharides. In recent years, pharmacologists have turned their attention secondary metabolites due to its extensive application in the food, cosmetic and pharmaceutical industries and in biotechnology (Wijesekara et al., 2011). Macroalgae, the first marine organisms was explored for medicinal purposes (de Oliveira et al., 2012). Brown algae produce cyclic or acyclic short chain hydrocarbons, terpenoids, acetogenins, polyphenols, and terpenoid-aromatic compounds (Mcclintock \& Baker, 2001and Blunt et al., 2011). The exhibition of antimicrobial activities was considered as an effective indicator of the capacity of the seaweeds to synthesize bioactive secondary metabolites (Del Val et al., 2001). However, seaweeds have been reported to produce a great variety of metabolic compounds, which are not produced by terrestrial plants (Plaza et al., 2008). Seaweeds are known to be rich in proteins, minerals and polysaccharides as well as bioactive substances such as carotenoids, polyphenols, terpenoids, and tocopherols. (Airanthi et al., 2011) documented the presence of carotenoid pigments such as fucoxanthin and astaxanthin. Polyphenols such as phlorotannins were observed in green and brown seaweeds (Yoshie et al., 2002; Sugiura et al., 2006; \& Zou et al., 2008).

Today, there is a renewed interest in traditional medicines, remedies with no side effects and an increasing demand for more drugs from marine sources especially seaweeds which provide essential, economic, environmental, aesthetic and cultural benefits to humanity. This revival of interest in marine algal-derived drugs is mainly due to the current widespread belief that "green medicine" is safe and more dependable than the costly synthetic drugs, many of which have adverse side effects. Scientists have even started correlating the properties of seaweeds with their pharmacological activity. In future, more coordinated multidimensional research aimed at correlating marine natural products and phytochemical properties to specific pharmacological activities is expected (Dahanukar et al., 2000) thus, helpful to the rural communities and informal settlements. Several studies are currently being undertaken to isolate the active compound(s) by bioassay-guided fractionation from the algal species that show high biological activity during screening. Thus considering the immense pharmacological properties in marine resource- seaweeds especially of brown marine macro algae an attempt has been made in the present study with an aim to 
explore the qualitative phytochemical constituents of Turbinaria ornate and Turbinaria conoides using different extracts.

\section{MATERIALS AND METHODS}

\section{Study area}

Rameswaram is a town and a second grade municipality in the Ramanathapuram district in the South Indian state of Tamilnadu. It is island located on Pamban also known as Rameswaram Island, is connected to mainland India by the Pamban Bridge. Rameswaram is considered to be one of the holiest places in India and is the closest point from which to reach Srilankan India (The Hindu,2012). The town covers an area of $53 \mathrm{~km}^{2}$ (20sq $\left.\mathrm{mi}\right)$ and had a population of

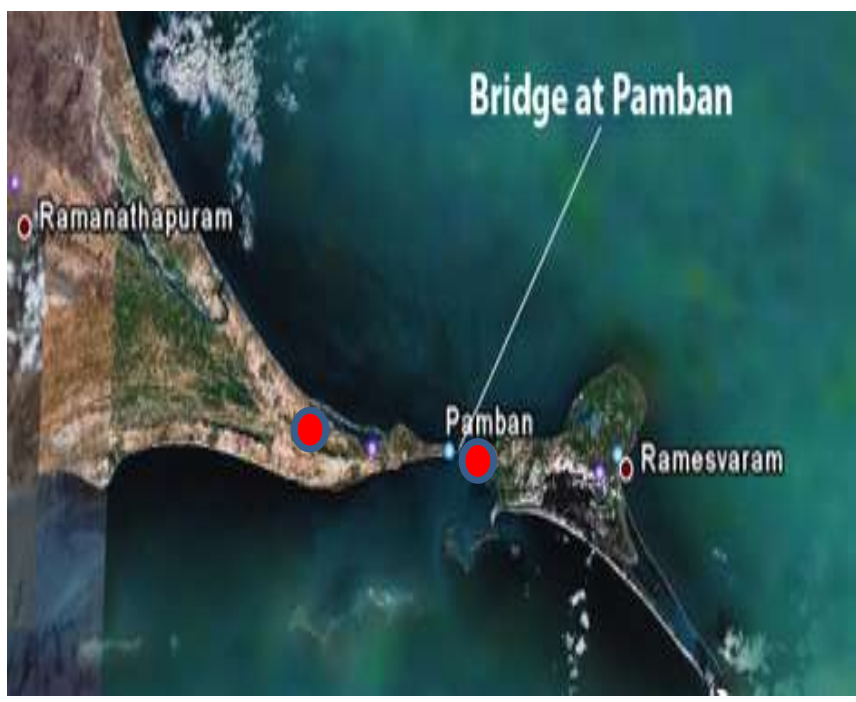

Plate: 2 Satellite map showing study area

\section{Sampling sites}

Rameswaram has an average elevation of $10 \mathrm{~m}$ (33ft).The island is spread across an area of $61.8 \mathrm{~km}^{2}(23.9 \mathrm{sq} \mathrm{mi})$ and is in the shape of a conch. $74 \%$ of the area has sandy soil due to the presence of sea and it has many islands surrounding it, the Palk Strait in the North West and Gulf of mannar in the South East (Ramanathapuram District Administration, 2011). (Plate: 2\&3).

Mandapam is a famous tourist attraction in Rameswaram with one of the best beaches. This beach is a calm place with the silent tides.

There is a good water spring situated inside the sea. A Sea Bridge connects Rameswaram on Pamban Island to Mandapam in Tamilnadu.

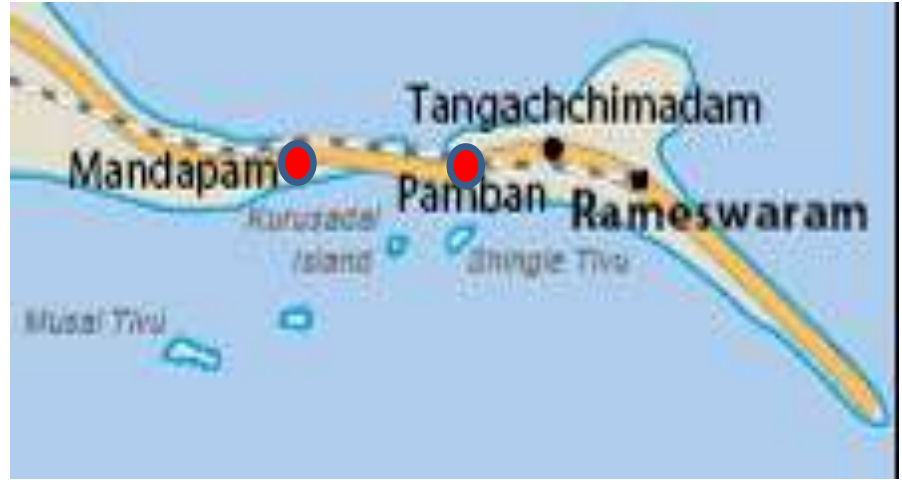

Plate: 3 Map showing the sample collection area 


\section{Collection of macroalgae}

Seaweed was collected during the lowest tide of chart datum from the seaweed infested locations along the Southeast coast of India, Rameswaram $\left(9.288^{\circ} \mathrm{N}\right.$ and $\left.79.313^{\circ} \mathrm{E}\right)$ Ramnadu district, Tamilnadu, India. The macroalgae which infested exclusively on the intertidal rocky and other substratum was selected for the collection as to avoid other microalgal contamination. The seaweed samples were collected from spots like Mandapam (Latitude: 9.2770392 and Longitude: 79.1252174) and Pamban bridge (Latitude: 9.2761; Longitude: 79.1867.) of

Rameswaram East coast of Tamilnadu, India. (Plate: 3). The live and healthy macro algal sample was collected by handpicking method at a depth of 1-2m during the month Dec 2020, from sandy beaches and irregularly distributed rocky substratum, of Mandapam beach and Pamban bridge of Rameswaram, Ramnad District, Tamilnadu, India.

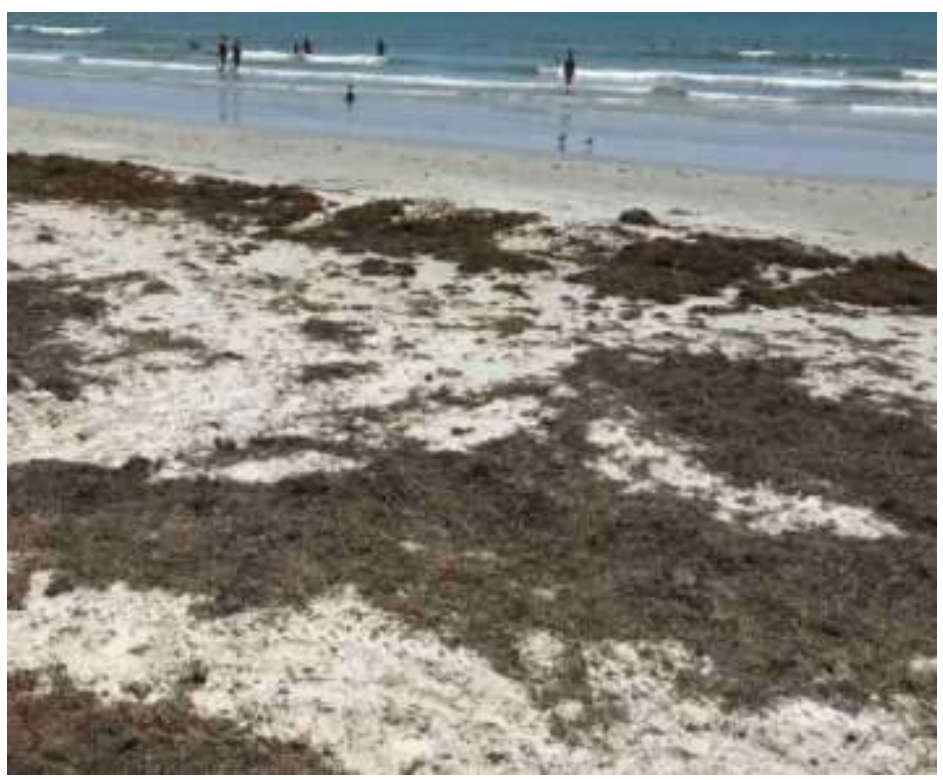

Plate: 4 Collection of Seaweeds from Mandapam beach

\section{Preservation of seaweeds:}

Immediately after collection the surface of seaweed was washed to avoid other algal contamination. They were washed in fresh sea water to eliminate the epiphytes, extraneous matter course sand and other calcareous impurities from the Pamban Bridge and Mandapam area of Rameswaram, Ramnadu district Tamilnadu, India. The collected macroalgae samples are transported to the laboratory in polythene bags under ice at $20^{\circ} \mathrm{C}$ to avoid decomposition and loss of metabolites for identification and future reference.

\section{Identification of macroalgae}

The seaweed thus collected was identified with the help of seaweed taxonomist in Centre for Marine Fisheries Research Institute (CMFRI) Mandapam camp Tamilnadu, India (Plates: 5\&6) 


\section{Scientific classification of identified seaweed}

\section{Study Species: I}

Domain : Eukaryota

Phylum : Heterokontophyta

Class : Phaeophyceae

Order : Fucales

Family :Sargassaceae

Genus :Turbinaria

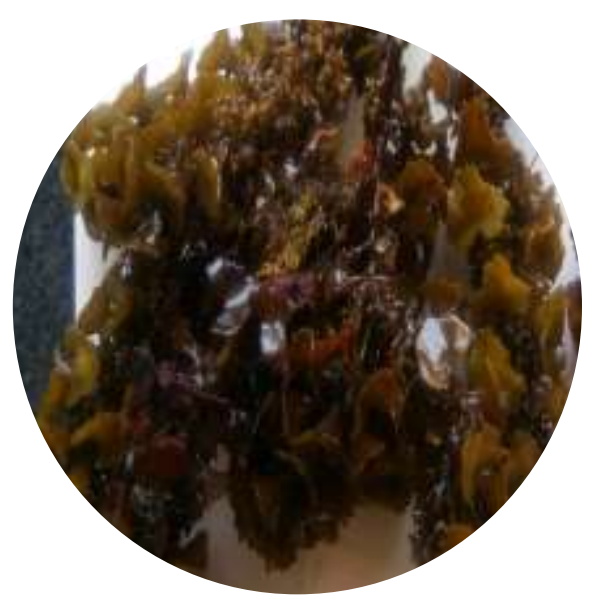

Species :Turbinaria ornate (Tuner)

\section{Plate: 5 Turbinaria ornate}

Common name: Crowded sea bell

Environment: Rocky intertidal areas, reef flats, deep water; mid intertidal to at least $30 \mathrm{~m}$

Climate / Range: Tropical and Sub tropical

Distribution: Asia, South America, Africa, Indian Ocean island, china, Pacific island, Singapore, Mayanmar, Vietnam, Arabian Gulf, India, Sri Lanka, Coral Sea Islands Territory, Northern Territory, New Guinea, Queensland, Western Australia, Aldabra Islands, Andaman Islands, Archipelago, Christmas Island, Comoros and Mayotte, Diego Garcia Atoll, Laccadive Islands, Maldives, Nicobar Islands, Réunion, Rodrigues Island, Seychelles.

Short description: Thalli erect and tough, dark brown, attached to rocky substrate by coarse branched holdfasts. Alternating turbinate, fleshy leaves with a terete stalk, crowded along the erect axis; distal end of leaves expanded to form a somewhat circular and fleshy marginal blade, outlined by sharp and coarse teeth; centre of blade concave and conspicuously surrounded, partially or fully, by a crown of teeth; single vesicles may be found at the depressed centre, usually among the leaves at the upper portion of the thallus. Receptacular 
branches racemose, 5 to $7 \mathrm{~mm}$ long, attached to the stalk of the leaves, about 1/3 the distance from the base, their distal portions irregularly forked. Thalli up to $17 \mathrm{~cm}$ in height (Plate: 5).

\section{Study Species: II}

Domain : Eukaryota

Phylum : Heterokontophyta

Class : Phaeophyceae

Order : Fucales

Family :Sargassaceae

Genus :Turbinaria

Species :Turbinaria conoides ( (J. Agardh)

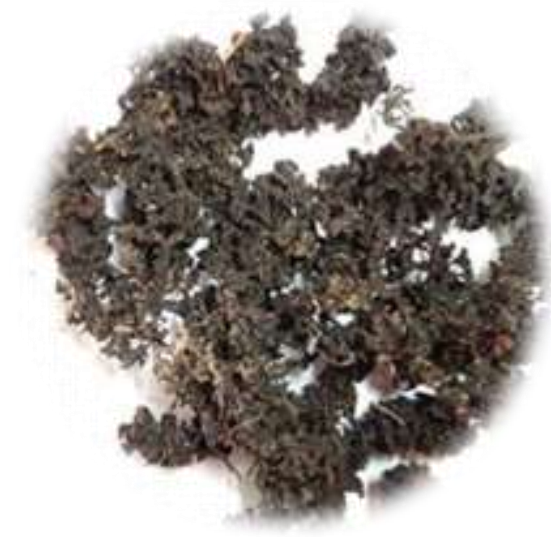

Plate: 6 Turbinaria conoides

\section{Common name: Sea bell}

Environment: Rocky intertidal areas, reef flats, deep water; mid intertidal to at least $30 \mathrm{~m}$

Climate / Range: Tropical and Sub tropical

Distribution: Tropics and subtropics of Indian and Pacific Oceans. China, Japan, Vietnam, Thailand, Malaysia, Singapore, Indonesia, Philippines, Australia, New Zealand, Pacific Islands.

Short description: Thallus erect, coarse, leathery, yellowish brown to dark brown, bushy, forming colonies, 20-30(-50) $\mathrm{cm}$ high. Main axes terete, to $3 \mathrm{~mm}$ broad, muricate below (because of shed branches). Branching from all sides. Branches 6-9(-20) cm long. Phylloids long-stalked (12-15 mm), turbinate, 10-15 mm long, 10-15 mm broad at distal end. Distal marginal phylloids irregularly triangular, irregularly rounded or lobed, sometimes cut deeply on one side, with single margins bearing sharp teeth; tips flat or concave. The stalk subterete to slightly triangular. Vesicles embedded in center of phylloids. Cryptostomata scattered over phylloids and stalk. Receptacles 3-7 mm long, forked, clustered at the basal portion of the 
phylloid stalks. Attachment by discoid holdfast and branched stolons. Growing on rocks, dead corals, in the lower intertidal to the upper subtidal zones, exposed to wave action. (Plate:6)

\section{Preparation of powder}

The identified species washed thoroughly with tap water until unwanted impurities, adhering sand particles and extraneous matter like epiphytes, pebbles, surface salty matures shells, were removed and rinsed with sterile distilled water spread on filter paper and left few hours to absorb the excess water and then cut into small pieces, shade dried for two weeks and later the samples were made into coarse powder by grinding them in an lab electric mixer grinder. The powdered sample were then stored in refrigerator. They were then screened for the evaluation of their phytochemical screening and antibacterial activity.

\section{Extraction of shade dried plant material}

The secondary metabolites were extracted by using soxhelt apparatus. The algal power was mixed with different solvents with increasing polarity Chloroform, Ethanol, Methanol, Acetone and Water (1:5 w/v) and placed into a soxhlet apparatus at $50^{\circ} \mathrm{C}$ for $24 \mathrm{hrs}$ the extraction was filtered using whatman No 1 filter paper. After extraction was complete, the solvent was then evaporated under vaccum and then the residue crude obtained was stored in a freezer at $-20^{\circ} \mathrm{C}$ for preliminary phytochemical analysis and antibacterial assay. (Becerro et al., 1988; Murugan and Santhanaramasamy,2003; Kanjana et al., 2011; Krishnaveni et al., 2012;).

\section{Preparation of seaweed solvents extract on phytochemical screening}

The dried, powered sample was subjected to qualitative test for the amount of phytochemicals present in the collected algal samples for identification of phytochemical constituents according to standard procedures (Lala, 1993).

\section{Phytochemical analysis in different solvent extract}

The phytochemical analysis of chloroform, ethanol, methanol, acetone and water extract from selected algae were screened for the presence or absence of active secondary metabolities such as alkaloids, phenols, flavonoids, anthraquinones, tannins, saponins, coumarins, carbohydrate, proteins, quinines, glycosides and terpenoids. General reaction in these analyses revealed the presence or absence of the compounds in the algal extracts in 
following procedures. The phytochemicals of the extracts were determined qualitatively as reported by (Trease and Evans,1989; Sadasivam and Manickam, 1996).

\section{Test for Alkaloids:}

$1 \mathrm{ml}$ of $1 \% \mathrm{HCl}$ was added to $3 \mathrm{ml}$ of extract in a test tube and was treated with few drop of Meyer's reagent. A creamy white precipitate indicted the presence of alkaloids.

\section{Test for Phenols:}

Ferric Chloride Test: Extracts were treated with 3-4 drops of ferric chloride solution. Formation of bluish black colour indicates the presence of phenol.

\section{Test for Flavonoids:}

A few drops of $1 \% \mathrm{NH}_{3}$ solution was added to the extract in a test tube. A yellow coloration was observed for the presence of flavonoids.

\section{Test for Anthraquinones:}

For Anthraquinone identification, $1 \mathrm{ml}$ of plant extract few drops of $10 \%$ ammonia solution was added, appearance of pink color precipitate indicates the presence of anthraquinones.

\section{Test for Tannins:}

To $0.5 \mathrm{ml}$ of extract solution, $1 \mathrm{ml}$ of distilled water and 1-2 drops of ferric chloride solution were added and observed for brownish green or a blue black coloration.

\section{Test for Saponins:}

$5 \mathrm{ml}$ of extract was shaken vigorously to obtain a stable persistent froth. The frothing was then mixed with 3 drops of olive oil and observed for the formation of emulsion, which indicated the presence of saponins. 


\section{Test for Coumarins:}

For coumarins identification, $1 \mathrm{ml}$ of extract, $1 \mathrm{ml}$ of $10 \% \mathrm{NaOH}$ was added. Formation of yellow colour indicates presence of coumarins.

\section{Test for Carbohydrates:}

Mix $2 \mathrm{ml}$ of plant extract, $1 \mathrm{ml}$ of molisch's reagent and few drops of conc. Sulphuric acid were added. Purple or reddish color indicates the presence of carbohydrates.

\section{Test for Proteins:}

To $2 \mathrm{ml}$ of extract $1 \mathrm{ml}$ of $40 \% \mathrm{NaOH}$ solution and 2 drops of $1 \% \mathrm{CuSo}_{4}$ solution was added. A violet color indicates presence of peptide linkage molecule.

\section{Test for Quinones:}

For quinines identification, $1 \mathrm{ml}$ of extract, $1 \mathrm{ml}$ of concentrated sulphuric acid was added. Formation of red color indicates presence of quinines.

\section{Test for Glycosides:}

$10 \mathrm{ml}$ of $50 \% \mathrm{H}_{2} \mathrm{SO}_{4}$ was added to $1 \mathrm{ml}$ of extract in a boiling tube. The mixture was heated in boiling water for $5 \mathrm{~min}$. $10 \mathrm{ml}$ of Fehling's solution ( $5 \mathrm{ml}$ of each solution A and B) was added and boiled. A brick red precipitate indicated presence of glycosides

\section{Test for Terpenoids:}

$5 \mathrm{ml}$ of extract was mixed with $2 \mathrm{ml}$ of $\mathrm{CHCl}_{3}$ in a test tube. $3 \mathrm{ml}$ of concentrated $\mathrm{H}_{2} \mathrm{SO}_{4}$ was carefully added to the mixture to form a layer. An interface with a reddish brown coloration was formed for the presence of terpenoids

\section{RESULTS AND DISCUSSION}

Seaweeds are potential renewable resources in the marine environment. Since ancient times, macroscopic marine algae has been closely associated with human life and has been exhaustively used in numerous ways as a source of food, feed, fertilizer and medicine, and chiefly used for economically important phycocolloids (Levering et al., 1969; Chapman, 
1970). Marine algae contain more than 60 trace elements in a concentration much higher than in terrestrial plants.

They also contain protein, iodine, bromine, vitamins and substances of stimulatory and antibiotic nature. The phytochemicals from marine algae are extensively used in various industries such as food, confectionary, textile, pharmaceutical, dairy and paper, mostly as gelling, stabilizing and thickening agents. In addition to vitamins and minerals, seaweeds are also potentially good sources of proteins, polysaccharides and fibres (Lahaye, 1991; DarcyVrillon, 1993).

Since there are numerous reports on compounds derived from macro algae with broad ranges of biological activities, such as the antimicrobial, antiviral, anti-tumour, antiinflammatory, and neurotoxic the present study was performed to investigate the phytochemical constituents of two selected brown seaweeds Turbinaria ornate and Turbinaria conoides such as alkaloids, flavonoids, steroids, terpenoids and tannins etc. which are presented in Tables (1\&2).

\section{Qualitative analysis of phytochemical substance screening in seaweed}

\section{Turbinaria ornate}

In the current study, marine seaweed Turbinaria ornate was extracted and screened for bioactive metabolite compounds using various solvents based on polarity. Qualitative analysis showed the presence of major bioactive compounds like alkaloids, phenols, flavanoids, glycosides, lipids, carbohydrates, proteins, tannins, oils, and fats. The marine environment has a great potential for the discovery of lead compounds that could be used against infectious diseases. Table 1 shows that qualitative analysis of phytochemicals of seaweeds powder Turbinaria ornate J.Ag. In the phytochemical analysis of Turbinaria ornata J. Ag., , twelve different types of secondary metabolites (alkaloids, phenols, flavonoids, anthraquinones, tannins, saponins, coumarins, carbohydrate, proteins, quinines, glycosides and terpenoids) were tested in five different extracts of Turbinaria ornata J.Ag.

Thus out of $(12 \times 5=60)$ tests for the presence or absence of the above compounds, only 26 gave positive results and the remaining 34 gave negative results. The 26 positive results showed the presence of alkaloids, phenol, flavonoids, tannin, saponins, quinines, coumarins, carbohydrates, glycosides and terpenoids. Anthraquinones and proteins did not 
show any positive result for their presence in any of the 5 extracts tested from Turbinaria ornata J.Ag. coumarins groups showed the maximum presence in the 5 different extracts followed by alkaloids, carbohydrate, quinines, glycosides and terpenoids. Among the 5 different extracts, methanol extract showed the presence of maximum number (10) of compounds. Next to that ethanol 8 compounds and acetone extract showed 6 compounds. Water and chloroform extracts showed 1 compound each (Table: 1)

In the present study methanolic and ethanolic extracts of Turbinaria ornate shows the presence of alkaloids, flavonoids, phenol, tannis, saponins, coumarins, carbohydrates, quinines, glycoside and terpenoids. Presence of these secondary metabolites known to be produced by plants and macro algae are of considerable pharmaceutical importance as they show antioxidant activity and their effects on human nutrition and they are used as drugs for the treatment of several diseases known to man and to maintain health (Evans, 2002). These secondary metabolites have been referred to as nature's biological response modifiers because of strong experimental evidence of their inherent ability to modify the body's reaction to allergen, virus and carcinogens.

Table: 1 Phytochemicals screening of different solvent extracted seaweed Turbinaria ornate

\begin{tabular}{|c|l|c|c|c|c|c|}
\hline S.No & Phytochemical & Chloroform & Ethanol & Methanol & Acetone & Water \\
\hline $\mathbf{1}$ & Alkaloids & - & - & + & + & + \\
\hline $\mathbf{2}$ & Phenols & - & + & + & - & - \\
\hline $\mathbf{3}$ & Flavonoids & - & - & + & - & - \\
\hline $\mathbf{4}$ & Anthraquinones & - & - & - & - & - \\
\hline $\mathbf{5}$ & Tannins & - & + & + & - & - \\
\hline $\mathbf{6}$ & Saponins & - & + & + & - & - \\
\hline $\mathbf{7}$ & Coumarins & + & + & + & + & - \\
\hline $\mathbf{8}$ & Carbohydrate & - & + & + & + & - \\
\hline $\mathbf{9}$ & Proteins & - & - & - & - & - \\
\hline $\mathbf{1 0}$ & Quinines & - & + & + & + & - \\
\hline $\mathbf{1 1}$ & Glycosides & - & + & + & + & - \\
\hline $\mathbf{1 2}$ & Terpenoids & - & + & + & + & - \\
\hline
\end{tabular}

*Abbr: $-=$ Absent,$+=$ Presence 
Next to methanol and ethanol, the acetone extract showed the presence six compounds, namely alkaloids, coumarins, carbohydrates, quinines, glycoside and terpenoids. Followed by acetone, chloroform showed the presence of coumarins and aqueous extracts showed the presence of only one compounds namely alkaloids (Table: 1). Presence of these bioactive molecules in various extracts of this seaweed may be responsible for various biological activities (antiviral, anti-inflammatory, and anticoagulant) Cumashi et al., 2007; Ghosh et al., 2009; Pomin and Mourao, 2008.

\section{Qualitative analysis of phytochemical substance screening in seaweed Turbinaria conoides}

The important phytochemical viz. alkaloids, glycosides, coumarins, flavanoids, phenols, proteins and free amino acids, quinones, saponins, sterols, teropinoids and sugars were screened for their presence and presented in Table-2.

The presence or absence of the phytochemicals depends upon the solvent medium used for extraction and the physiological aspect of the sea weeds selected. In the present study phenolic compounds were noticed in all the extracts of Turbinaria conoides. In general, phenolic compounds possessed specific physical, chemical and biological activities that make them useful as drugs. Phenolics were also responsible for the antimicrobial, antiinflammatory, anti-feedant, anti-viral, anticancer and vasodilatory actions (Aliyu et al, 2009). Saponins are considered as a key ingredient in traditional chinese medicine and are responsible for most of the observed biological effects. Saponins are known to produce effect on inflammation and it is commercially exported as dietary supplements (Manjunatha, 2006).

Table: 2 Phytochemicals screening of different solvent extracted seaweed Turbinaria conoides

\begin{tabular}{|c|l|c|c|c|c|c|}
\hline S.No & Phytochemical & Chloroform & Ethanol & Methanol & Acetone & Water \\
\hline $\mathbf{1}$ & Alkaloids & - & + & + & + & + \\
\hline $\mathbf{2}$ & Phenols & + & + & + & + & - \\
\hline $\mathbf{3}$ & Flavonoids & - & + & + & - & - \\
\hline $\mathbf{4}$ & Anthraquinones & - & + & - & - & - \\
\hline $\mathbf{5}$ & Tannins & - & + & + & - & - \\
\hline
\end{tabular}


EPRA International Journal of Research and Development (IJRD)

Volume: 6 | Issue: 5 | May 2021

- Peer Reviewed Journal

\begin{tabular}{|c|l|c|c|c|c|c|}
\hline $\mathbf{6}$ & Saponins & + & + & + & - & - \\
\hline $\mathbf{7}$ & Coumarins & + & + & + & + & - \\
\hline $\mathbf{8}$ & Carbohydrate & - & + & + & + & - \\
\hline $\mathbf{9}$ & Proteins & - & + & - & - & - \\
\hline $\mathbf{1 0}$ & Quinines & + & + & + & ++ & - \\
\hline $\mathbf{1 1}$ & Glycosides & - & - & + & + & - \\
\hline $\mathbf{1 2}$ & Terpenoids & + & + & - & + & - \\
\hline
\end{tabular}

*Abbr: $-=$ Absent, $+=$ Presence,

In the present study Saponins showed its presence in chloroform and ethanol extract. Tannins were found only in the ethanol extract of T.conoides. Tannins were used therapeutically as antiviral, antibacterial, antiulcer and antioxidant agents. Many tannin containing drugs are used in the treatment of piles, inflammation, burns and as astringent (Kolodziej et al., 2005). Steroids of plant origin are known to be important for insecticidal, antimicrobial, antiparasitic and cardiotonic properties. Steroids also play an important role in nutrition, herbal medicine and cosmetics (Okwu, 2001). Coumarins were noticed in chloroform, acetone and ethanol extracts. Coumarins have been used as anti-coagulant to treat lymphedema. The present study confirms the presence of tannins in chloroform and water extracts of Ethanol and Methonal extracts of Tubinaria ornate and Turbinaria conoides which suggest that it can be used as antimicrobial. Tannins were used therapeutically as antiviral, antibacterial, antiulcer and antioxidant agents. Many tannin containing drugs are used in the treatment of piles, inflammation, burns and as astringent (Kolodzies and Kiderlen, 2005; Rivere et al., 2009). Flavonoids, being the major group of phenolic compound reported for the antimicrobial, antiviral and spasmolytic activity when supplemented in human diet may reduce risk of various cancers, as well as preventing menopausal symptoms. Antitumor and antioxidant properties have been attributed to the flavonoids based on invitro and invivo studies both in human and in animals. (Cody et al., 1998). Phenolics are the largest group of phytochemicals accounting for most of the antioxidant activity of seaweed or seaweed products. According to Aliyu et al., 2009, phenolics were responsible for antimicrobial, antiinflammatory, antifeedant, antiviral, anticancer and vasodilatory action. 
The present phytochemical study revealed the presence of higher concentration of proteins, alkaloids, moderate amount of tannins and traces of cardioglycosides. These constituents significantly contribute to the biological activity of seaweeds (Katayama, 1962, Takagi, 1975). The results obtained in present study are in concordance with (Periasamy Mansuya et al., 2010).

Nowadays, higher percentage of population refers to use remedies of natural origin for curing illness as these claims to produce fewer side effects (Tyagi and Bohra, 2002). Seaweeds, one of the major marine algae provide a rich source of structurally diverse and biologically active secondary metabolites. The functions of these macro algae secondary metabolites are raising defence mechanism against herbivores, fouling organisms and human disease causing pathogens. Research has also shown that marine derived plant can produce a vast array of natural products with great diversity in chemical structure.

\section{CONCLUSIONS}

Based on the results obtained from the present study, it can be concluded that the presence of alkaloids, phenolics, flavonoids, saponins, tannins, carbohydrates, carboxylic acid, coumarines, xanthoproteins and anthroquinones from Turbinaria ornata and Turbinaria conoides. This report will lead to the isolation and characterization of these active secondary metabolites for bioefficacy and bioactivity. Therefore, the exploration of seaweeds using new tools and techniques, such as those of high-throughput genomic and metagenomic approaches, will led to the discovery of more novel bioactive natural products in future, and will help in exploiting their biotechnological potential. The prevention and treatment of these infectious diseases by applying products from marine organisms appears as a possible alternative.

\section{BIBLIOGRAPHY}

1. Airanthi M., K. Widjaja-Adhi., Masashi Hosokawa., Kazuo Miyashita._(2011). Comparative antioxidant activity of edible Japanese brown seaweeds. Journal of Food Science 76(1):C104-11.

2. Aliyu, A.B., Musa. A.M., Sallau, M.S, and Oyewale, A.O. (2009). Proximate composition, mineral elements and anti-nutritional factors of Anisopus mannii N.E.Br. (Asclepiadaceae). Trends in Applied Sciences Research. 4(1): 68-72.

3. Anon, (2005). Seaweeds: Wonder plants of the sea (Ed. Krishnamurthy, V.), Aquaculture Foundation of India, Chennai, 30

4. Barsanti L and Gualtieri P. (2006). Algae anatomy, Biochemistry and Biotechnology. Taylor and Francis. 
5. Becerro, M.A., N.I. Lopez, X. Turon and M.J. Uniz, 1988. Antimicrobial activity from marine and freshwater microalgae in laboratory culture. British Phycological Journal. 23: 45-47.

6. Blunt JW, Copp BR, Munro MHG, Northcote PT, Prinsep MR. (2011). Marine natural products. Nat Prod Rep 28(2):196-268.

7. Chapman V.J. (1970). Seaweeds and Their Uses. (second ed.), The Camelot Press Ltd., London and Southampton, pp. 63-85.

8. Cody, V., Middleton,E., Harborne, J.B. and Baretze, A.(1988).Plant flavonoids in biology and medicine, Biochemical, cellular and medicinal properties. Alan R. Liss Inc, New York.

9. Cumashi, (2007). A comparative study of the anti-inflammatory, anticoagulant, antiangiogenic, and antiadhesive activities of nine different fucoidans from brown seaweeds, Consorzio Interuniversitario Nazionale per la Bio-Oncologia (CINBO), Italy,541-552.

10. Dahanukar, S.A., Kulkarni R.A. and Rege, N.N. (2000). Pharmacology of medicinal plants and natural products. Indian Journal of Pharmacology. 32: S81-S118.

11. Darcy-Vrillon B (1993) Nutritional aspects of the developing use of marine macro algae for the human food industry. International Journal of Food Science and Nutrition 44: 23- 35.

12. Del Val AG, Platas G, Basilio A, Gorrochategui J, Suai I, Vicente F, Portillo E, Del Rio MJ, Reina GG., Pelaez. F. (2001) Screening of antimicrobial activities in red, green and brown macroalgae from Gran Canaria (Canary Islands, Spain). Int. Microbiol, 4: 35-40

13. Evans WC (2002). Trease and Evans Pharmacognosy, 15th edition. W.B Sauders Company Ltd, London. pp 137-139,230-240

14. Ghosh, T., Auerochs, S., Saha, S., Ray, B., Marschall, M., (2010). Anti-cytomegalovirus activity of sulfated galactans generated from a commercial preparation of rice bran. Antiviral Chem. Chemother. 21: 85-95.

15. Kanjana, K., Radtanatip, T., Asuvapongpatana, S., Withyachumnarnkul, B. and Wongprasert, K. 2011. Solvent extracts of the red seaweed Gracilaria fishri prevent Vibrio harveyi infections in the black tiger shrimp Penaeus monodon. Fish and Shellfish Immunology. 30: 389-396.

16. Katayama, A., (1962). Volatile constituents. In (R. A. Lewin, Ed.) Physiology and Biochemistry of Algae, Academic Press, New York, 467-473.

17. Kolodziej, H. and Kiderlen, A.F. (2005). Antileishmanial activity and immune modulatory effects of tannins and related compounds on Leishmania parasitised RAW 264.7 cells. Phytochemistry. 66(17):2056-2071.

18. Krishnaveni ,K., Mureshkumar, D.J., Balakumaran, M.D., Ramesh, S. and kalaichelvan, P.T.( 2012). Production and optimization of extrcellular alkaline protease from bacillus subtilis isolated from dairy effulent. Der Pharmacia Lett.4(1)98-109 Lala, P,K. (1993). Lab manuals of Pharmacognosy. CSI publishers and distributers, Calcutta.

19. Lahaye, M. (1991). Marine algae as a source of dietary fibers -determination of soluble and insoluble dietary fiber contents in some 'sea vegetable'. Journal of the Science of Food and Agriculture.54:587-594.

20. Lala, P,K. (1993). Lab manuals of Pharmacognosy. CSI publishers and distributers, Calcutta.

21. Levering,T. H.A. Hoppe, O.J. Schimid (1969).Marine Algae. A Survey of Research and Utilization. Granm be Gruyter Hamburg, pp. 1-420

22. Li Y, Qian ZJ, Ryu B, Lee SH, Kim MM, Kim SK. (2009). Chemical components and its antioxidant properties in vitro: an edible marine brown alga, Ecklonia cava. Bio org Med Chem.17:1963-1973

23. Manjunatha, B. K. (2006). Antibacterial activity of Pterocarpus santalinus. Indian journal of pharmaceutical sciences, 68(1): 115.

24. Maria Jose Perez, Elena Falque and Herminia Dominguez. (2016). Antimicrobial Action of Compounds from Marine Seaweed. Mar. Drugs, 14(52);1- 38.

25. Mcclintock, J. B. and B. J. Baker. (2001). Marine Chemical Ecology. Series in Marine Science, Volume 25. CRC Press, London, England. 
26. Murugan, A. and M. Santhana Ramasamy, 2003. Biofouling deterrent natural product from the ascidian Distaplianathensis. India Journal of MarineScience.32: 162-64.

27. Okwu, D.E. (2001). An improving Nutritive value of cassava tapioca meal with local spices. Journal of Nutraceutical, Functional and medical food, 3:43-51.

28. Oliveira, A. S. de; Schwambach, T. I.; Sinhorin, A. P, Oliveira, M. R. C. Alessi, K. A. ; Filho, F. A. de O. ; Pina, D. dos S., 2012. Capacity of ensilage of Jatropha curcas L. cake to degrade phorbol esters. Rev. Bras. Zoot., 41 (6): 1545-1549.

29. Periasamy Mansuya, Pandurangan Aruna, Sekaran Sridhar, Jebamalai Sureah Kumar and Sarangam Babu, (2010). Antibacterial activity and qualitative phytochemical analysis of selected Seaweeds from Gulf of Mannar region. Journal of Experimental Sciences. 1(8):23-26.

30. Plaza, M. Amigo-Benavent, M. Del Castillo, M.D. Ibáñez, E. Herrero, M. (2010). Facts about the formation of new antioxidants in natural samples after subcritical water extraction. Food Res. Int., 43: 2341-2348.

31. Pomin, V. H., \& Mourão, P. A. S. (2008). Structure, biology, evolution, and medical importance of sulfated fucans and galactans. Glycobiology, 18(12):1016-1027.

32. Rivere , C., Van Nguyen, J.H., Pieters, L., Dejaeegher, B., Heyden, Y.V. and Minch, C.V.(2009). Polyphenols isolated from antiradical extracts of Mallotus metacalfianus. Phytochemistry.70:86-94.

33. Sadasivam, S. and Manickam, A. (1996). Biochemical methods for agricultural sciences, New age International (P) Ltd., New Delhi, India, 1-97.

34. Sugiura, Y., Matsuda, K., Yamada, Y., Nishikawa, M., Shioya, K., Katsuzaki, H., Imai, K.,Amano, H., (2006). Isolation of a new anti-allergic phlorotannin, phlorofucofuroeckol-B, from an edible brown alga, Eisenia Arborea. Biosci. Biotechnol. Biochem. 70:2807-2811.

35. Takagi. M., (1975). Seaweed as medicine. In: Advance of Phycology in Japan (Jan Tokida and Hirose Jena, G. Fisher, Ed.) 321-325.

36. Trease GE, Evans MD. A text book of Pharmacognosy, 13th Edn.Baillier, Tindal and Caussel, London.1989, 144-148.

37. Tyagi N, Bohra A. (2002).Screening of phytochemicals of fruit plant and antibacterial potential against Pseufomonas aeruginosa. Biochem Cell Arch.;2:21-24.

38. Wijesekara, I. Kim, S.K. Li, Y.X. Li, Y.X. (2011). Phlorotannins as bioactive agents from brown algae. Process Biochem., 46: 2219-2224.

39. Yoshie Y, Wang W, Petillo D, Suzuki T. (2000). Distribution of catechins in Japanese seaweeds. Fish Sci. 66:998-1000.

40. Zhao, Z.H., Liu, M.J., Tu, P.F., (2008). Characterization of water-soluble poly saccharides from organs of Chinese Jujube (Ziziphus jujuba Mill. cv. Dongzao). Eur. Food Res.Technol. 226: 985-989. 